\title{
WestVirginiaUniversity
}

THE RESEARCH REPOSITORY @ WVU

Graduate Theses, Dissertations, and Problem Reports

2016

\section{Withdrawn: Why Students of Color Leave WVU}

Ahnieyah Porter

Follow this and additional works at: https://researchrepository.wvu.edu/etd

\section{Recommended Citation}

Porter, Ahnieyah, "Withdrawn: Why Students of Color Leave WVU" (2016). Graduate Theses, Dissertations, and Problem Reports. 7118.

https://researchrepository.wvu.edu/etd/7118

This Thesis is protected by copyright and/or related rights. It has been brought to you by the The Research Repository @ WVU with permission from the rights-holder(s). You are free to use this Thesis in any way that is permitted by the copyright and related rights legislation that applies to your use. For other uses you must obtain permission from the rights-holder(s) directly, unless additional rights are indicated by a Creative Commons license in the record and/ or on the work itself. This Thesis has been accepted for inclusion in WVU Graduate Theses, Dissertations, and Problem Reports collection by an authorized administrator of The Research Repository @ WVU. For more information, please contact researchrepository@mail.wvu.edu. 
Withdrawn: Why Students of Color Leave WVU

\author{
Ahnieyah Porter \\ Thesis Submitted to the \\ Eberly College of Arts and Sciences \\ At West Virginia University \\ in partial fulfillment of the requirements \\ for the degree of \\ Master of Arts \\ In \\ Sociology \\ Jesse Wozniak, Ph.D., Chair \\ Jason Manning, Ph.D. \\ Joshua Woods, Ph.D. \\ Department of Sociology and Anthropology \\ Morgantown, West Virginia \\ 2016
}

Keywords: Predominately white institutions, student departure, African American persistence Copyright 2016 Ahnieyah Porter 


\section{Abstract \\ Withdrawn: Why Students of Color Leave WVU}

Ahnieyah Porter

This study conceptualizes Vincent Tinto's theory of Individual Departure of college students and expands it to examine how it applies to the experiences of students of color, African Americans, who attend a predominately white institution that is West Virginia University. Tinto's theory measures individual departure in three stages; Separation, Transition and Incorporation. Using qualitative interviews, both former and current African American undergraduate students from West Virginia University were interviewed to discuss their experiences as students of color at a predominately white institution. The interview questions were designed to touch on each stage of Tinto's theory of Individual departure in order to determine how his theory directly effects African American students at West Virginia University. 


\section{WITHDRAWN: WHY STUDENTS OF COLOR LEAVE WVU}

\section{Table of Contents}

Table of contents............................................................................................ii

Chapter One: Introduction................................................

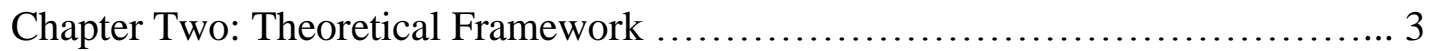

Chapter Three: Methods ................................................. 10

Chapter Four: Results .................................................13

Chapter Five: Discussion ............................................20

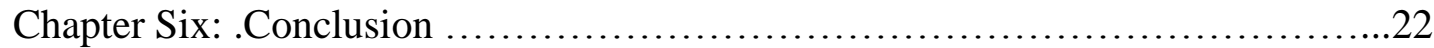

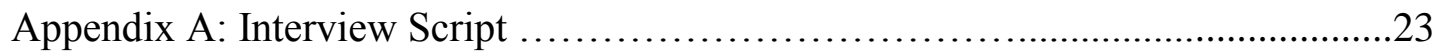

Appendix B: IRB Grant Exemption Notice..................................26

References: ........................................................ 28 


\section{Introduction}

Since the year 2004, West Virginia University has experienced a steady increase in enrollment of African American students, but the retention rate of these students does not coincide with the steadily rising enrollment rates. It may come as no surprise that a predominately white institution with 29,707 students and only $4.71 \%$ being African American that African American students tend to withdraw. In spring of 2012 I began working closely with West Virginia University’s associate provost who became concerned about the declining retention rate of students of color and wanted to create a program in which she could speak with African-American students face to face and have them voice their concerns and issues about the conditions on campus and what steps she could take to improve them.

Through assisting and facilitating this program I too became interested and concerned as to what these reasons were. Why are students of color leaving the university? Research suggests that many African American students have not had overall positive experiences at predominately white institutions (PWIs). Students of color were reported of having lower persistence rates, lower academic achievement levels, less likelihood of enrollment in advanced degree programs,

poorer overall psychological adjustment, and lower graduation and occupational earnings (Love, 2008). Due to difficulties in social and academic adjustments at PWIs the probability of successful completion for many African American students are slim (Braddock, 1981). Another study conducted by Mow and Nettles (1990) on African American students who attended PWIs shows that nearly $90 \%$ of these students reported feelings of isolation and loneliness which in turn encouraged their decision to withdraw from the university. They also reported lack of access to campus networks that were available to their white classmates. These students viewed themselves as invisible and not a part of the broader culture that existed at their institution. 
WVU recognizes this issue and has attempted to take action. WVU is initiating a 2020 plan (strategicplan.wvu.edu). The 2020 plan implements a set of strategic plans to ensure the success of WVU students. Goal number three of this plan was to improve the retention rate of minorities. In the fall of 2014 WVU enrolled its highest number of African-American students since the year 2004 with 2,252 students. Although the enrollment rate of black students is increasing the retention rate of these students is not seeing the same effect. This issue of low retention rates of minorities is not unique to WVU. Throughout the 1990's the national college dropout rate for African Americans was 20-25\% higher than that of white students (Davis et al., 2004).

The overall retention rate at WVU is $77.0 \%$, but the retention rate for minority students is less than $50 \%$. This data coincides with a study completed by Derrick Love of The Academy of Educational Leadership that $70 \%$ of African American students who attended predominately white institutions do not complete their baccalaureate education as compared to the $20 \%$ of those who attend historically black colleges and universities (HBCU) (Love, 2008).

By completing this study I hope to bring awareness of the phenomenon that is low persistence rates of African American students at PWIs. Furthermore, it is my hope that with the results of this study I will be able to aid institutions of higher education in implementing policies that will better the collegiate experiences African Americans have at WVU as well as their persistence rates.

The completion of this study has shown me ways in which my results can help richen sociology literature. Previous social theories on social interactions and how they affect college students, have not taken a complete look on how these interactions and their effects may differ 
between racial groups. Though the differences between racial groups has been slightly acknowledged, a solution on how to better these effects has not been proposed.

Tinto's theory of Individual Departure slightly touches on African Americans, but his findings are generalized to be applicable to all racial groups. Following completion of this study I found that to not be the case. Some aspects of his theory were applicable to the African American population while others were not. The goal of this study is to take the current literature one step further and bridge that gap and provide evidence to support possible solutions to better the effects social interactions have on African American students who attend PWIs.

\section{Theoretical Framework}

The theoretical framework of this research is based upon the works of Vincent Tinto and his theory of individual departure as it relates to the academic success of all students attending institutions of higher education. I expanded Tinto's theory to examine how it applies to the experiences of African Americans who attend predominately white institutions. Tinto (1972) posits a theory of individual departure from institutions of higher education in which he utilizes a longitudinal model. Tinto modeled his work from that of social anthropologist Arnold Van Gennep and his study of the rites of passage in tribal societies. Gennep was concerned with, "the movement of individuals and societies through time with the mechanisms which promote social stability in times of change" (Gennep, 1960, p. 8). He viewed life as a series of passages which individuals experienced multiple transitions into one group or status to another. He was concerned with the question of societal revitalization over time and with the general problem of social stability in times of change (Tinto, 1972, p. 94). In broader terms, his concerns reflected an interest in the types of mechanisms traditional societies implemented to ensure a successful transmission of its social relationships over time. 
Tinto linked Gennep's concern of the movement of individuals from membership in one group to that of another, especially in individuals who make the transition from youth to adulthood, directly to his ideas of student departure. Gennep believed that the process of transmission of relationships between succeeding groups in these tribal societies is marked by three stages: separation, transition, and incorporation. "The individual or group leaves an old territory or community (separation), in some fashion crosses a boarder, whether it be physical or ceremonial, to a new setting (transition), and takes up residence in the new location or community" (incorporation) (Tinto, 1972, p. 93). These three stages were thought to be the key components of an individual transitioning from youth into an adult society.

Tinto believed that similar conflicts are presented to individuals who experience difficulty navigating those early passages to membership in the communities of the institution in which they attend. He argued that these ideas provide us with a way thinking about the longitudinal process of student persistence in college and about the time-dependent process of student departure. The use of Gennep's three stages can help frame the stages in which students go through prior to their decision to depart from institutions of higher education thus leading to the development of his theory of "individual departure".

Tinto described the first stage of separation for college students as separation from membership in communities of the past such as high school, family and local areas of residence. These past communities differ from college in terms of values, norms and intellectual styles. $\mathrm{He}$ argues that a successful transition into these college values and norms involve some form of rejection from past communities and some degree of transformation.

Students of color who are from predominately African American communities now must transition into a predominately white one. On average more than $70 \%$ of black students at PWIs 
attended prior schooling with more than $50 \%$ minority enrollment (Davis et al., 2004). The separation from their predominantly black community into a predominantly white one may force students to some degree reject their cultural norms. The effects of rejecting cultural norms and adapting new ones was examined by Joe R. Feagin and Melvin P (1995). They reported African American Students are pressured to give up identities and adapt to surrounding white culture including white middle class ways of talking, dressing and acting. Adapting and rejecting culture on campus also potentially posits an issue within the black community as well (Feagin \& Sikes 1995). Previous studies show many black students report having difficulty connecting with white students because it was viewed by their black peers as "trying to be like them" and "rejecting their own culture completely" (Davis et al., 2004).

The second stage, transition, is what Tinto defines as the time between high school and college. This is the period of passage between the old and the new norms and values that will be adapted in college. During this stage students are neither strongly bound to the past nor firmly tied to the future. He notes that the degree of change during the transition phase is dependent upon the degree of difference between the norms and patterns of behavior associated with membership in past communities and those required for integration into the life of the college (Tinto, 1972 p. 97). A successful transition is also dependent upon the degree to which students have begun the process prior to formal entry. This could be done through the completion of university related programming offered before the official start date of classes.

One such program that WVU offers is STARS (Students Reaching and Achieving for Success). STARS is a four week summer program that aims to prepare incoming African American freshmen students for the WVU experience through academic workshops, social and cultural activities. In addition to social and cultural activities the program includes three 
workshops as well. Students are also required to participate in a "Rites of Passage Program" which highlights the experiences and tribulations of the African American community.

Typically the STARS program accepts up to 15-20 participants each summer. To be eligible for the program students must identify as African American and must have a high school GPA of at least a 2.75. Students must also provide transcript evidence of extra-curricular activities, or proof of community service involvement. Students who meet these requirements and that are interested in the program may complete the application to participate online completed with an essay, official high school transcript and three letters of recommendation. The hope is that through these various activities these students will build a solid academic foundation, find a sense of belonging and remain at the university.

Initially many African American students who attend PWIs experience a significant culture shock when they arrive on campus. Students are not prepared for the subtle pressures to conform to white standards of dress, language and group behavior. This is partly due to the belief that some black parents do not sufficiently prepare their children for what the white college setting will be like (Feagin \& Sikes, 1995). The lack of preparation prior to arriving on campus may result in a poor transition and increase the chances of withdrawal.

The final stage, incorporation, is where the student faces the task of becoming integrated into the communities of their institution. At this point students have moved away from the norms and behaviors in their past communities and now face the challenge of adopting new ones appropriate to their college setting. Examples of ways one would incorporate with a college include joining sports teams, student associations and involvement in Greek life etc. 
Becoming integrated into the communities of PWIs may prove to be a challenge for black students. In fact, a study of students of color at PWIs found that $62 \%$ of black students at PWIs felt campus activities did not appeal to their interests. Most campus activities reflected the interest and traditions of white students and faculty. Students felt there was little willingness to incorporate black values, interests, or history into the core of campus culture. (Feagin \& Sikes 1995). The lack of black culture on campus may hinder black students from making some form of connection at the university inside and outside of the classroom. The inability to form a connection in some aspect could potentially contribute to dropout rates.

William E. Sedlacek (1976) also noted the importance of incorporation for African American students within their collegiate communities. Sedlacek examined 20 years of student affairs research on black undergraduates at PWIs. What he found was that there were seven noncognitive variables critical to the lives of minority students. These variables included, a positive self-concept or confidence, realistic self-appraisal, understanding and dealing with racism, demonstration of community service, preferring long-range goals to short-term ones, knowledge in an acquired field and availability of a strong support person. How students adjusted to these dimensions and how faculty and staff encouraged this adjustment determined the success or failure of the minority student.

I found that one of those non-cognitive variables, community service, was relevant to my study. Sedlacek defined community service as how involved a minority student was with his or her cultural community. According to Sedlacek, "Blacks need to have identification with and be active in a community in or off campus, large or small, but it will commonly be based on race" (1976). He believed black students needed a supportive group that could give them advice and comfort to sustain them as they confront the larger, often hostile systems of their PWIs. 
Although a great deal of Tinto's theory of individual departure is based on Gennep's three stages of transmission, he also examines how adjustment, difficulty, isolation, learning, pre-entry attributes, academic and social system bonds, and external obligations or commitments explain the longitudinal process by which individuals leave these institutions. Tinto's theory is represented by a longitudinal model that aims to explain how interactions among different individuals within the academic and social systems of the institution and the communities which comprise them lead individuals of different characteristics to withdraw from the university.

Although Tinto utilizes a longitudinal study, I used his model to complete a crosssectional study. My primary goal for this study is to implement change within the university that could aid the retention of African American students. A cross-sectional study would be quicker than a longitudinal study therefore implementing change faster. It is ideal that these suggested changes be relevant to the current student atmosphere. Since fall of 2009, the number of African American student enrollment at WVU has steadily increased. With that steady increase one could argue that the overall African American experience at WVU is constantly changing each year. It is for this reason I do not think studying the same participants over a period of time would be an accurate representation of current experiences and attitudes of African American students.

Although I did not utilize a longitudinal study, I believe Tinto's model would be the ideal tool to use to measure the persistence of African Americans at PWIs. The three stages of separation, transition, and incorporation are important to students of color at these institutions as previous research supports the notion that feelings of isolation and difficulties transitioning into the norms and values of these institutions are high among black students at PWIs. Also the examination of pre-entry attributes which include family background, skills and abilities, and prior schooling are also important when examining the African American population at WVU. A 
majority of the black students at WVU are out-of-state and report being from urban areas. These pre-entry attributes may play a role in why such a high number of students of color find difficulties integrating into these universities. WVU and predominately white institutions may be even more difficult to integrate into for those students of color who report being from urban areas. WVU is in a rural location and the surrounding areas around the university are predominately white.

At the core of Tinto's longitudinal model he examines institutional experiences and interactions within the academic and social systems of the institution and the communities which they comprise. Tinto believes that students with healthy bonds with both academic and social systems within the institution are more likely to remain at the university. He makes the point to say strong bonds in both academic and social systems because he sees the two as interrelated on many levels. For instance a bond you may make with members in a formal setting such as a club sport can quickly turn into peer group interactions outside of that setting which then becomes informal. Also one's social isolation could have negative effects on a student's academic performance. This is crucial for African American students because creating these bonds at an institution where many feel like outcasts could play a major role in increasing the persistence of these students.

From these studies I noticed a common theme - the feeling of isolation. Many black students are feeling as if they do not belong at these predominately white institutions and view themselves as outsiders. This feeling of isolation and lack of connection to the university as noted by Tinto and other scholars can be determinants of a student's academic success. These negative feelings are more likely to occur in black students who attend PWIs because they are not afforded the same dominant cultural atmosphere as their white peers. 


\section{Methods}

The following analysis was completed by analyzing data from interviews of current and former WVU students of color. By conducting interviews I was able to learn about the experiences of African American students on their own account and not by what theorists believe they may be going through. It was important that I interviewed both former and current WVU students because I felt the testimony of both not only gave depth to the study, but the data gathered from both groups will make my codes stronger because a particular idea or feeling could essentially be felt by two groups of students thus strengthening the importance/relevancy of a particular point.

Conducting interviews seemed to be the most appropriate from of data collection for this particular study. Other methods of data collection would not give me the detail needed to capture the true feelings of African American students at WVU. Although the same questions could have been asked via survey, witnessing firsthand the emotion attached to the words of the participants helped to indicate what was most important to them.

I also felt that I would be at an advantage by conducting the interviews being as though I am a student of color and a former WVU undergraduate student. By having this common experience I believe I had less trouble obtaining full truths from my subjects. Previous studies on race-of-interviewer effect help to illustrate my point. "The color of a person's skin is likely to influence how they respond. The known overall mistrust that black people have for white people will extend to the white researcher or interviewer" (Rhodes, 1994). This mistrust is believed to prevent access or distort the quality of the information given. Other studies on race-ofinterviewer effect highlight the importance of preferred roles of the interviewer - especially with African Americans. "The preferred role for African American interviewers to play is being 
committed to the 'black struggle'. This is a sign of power and courage as it challenges views as well as power of dominant culture" (Davis, 1997).

Although my interview topic cannot attest to the true definition of "black struggle", I am able to identify with my respondents as I too may have had similar negative feelings and experiences as a black undergraduate at a PWI. This commonality will aid me in gaining the trust and comfort of my respondents. Once the trust and comfort is established I am hopeful that the responses I receive are well thought out and honest. Though hopeful of this, I cannot ignore that honesty from my participants is not guaranteed which is a con of conducting interviews. Despite being the same race as participants, participants may still feel nervous amongst other emotions when being questioned face to face and this could result in answers that are not completely sincere.

I conducted a total of fifteen interviews with both current and former WVU students from all undergraduate levels through snowball/convenient sampling. I chose to use snowball sampling in order to gain access into groups around campus that were unfamiliar to me. With the black community at WVU being so small I wanted to avoid groups of people whom I interact with. Initiating contact with someone I had no prior relationship with helped them to lead me to others who were strangers to me as well.

A limitation of this sampling technique is not being able to represent all African American groups that exist on campus. This makes it difficult to infer that my findings can be a valid representation of the feelings of all African American students who attend or withdrew from WVU. 
Former WVU students have been located through contacts I have made through my assistantship. Through these contacts I have access to students who withdrew from the university, as well as those planning to withdraw following the completion of the spring 2016 term. Each interview was roughly an hour long. Interview questions were divided into three sections to accurately explore the three stages of Tinto's theory of student departure.

The first section of interview questions measured stage one, separation. These questions explored hometown descriptions, family background, prior education community evolvement, and values and beliefs. The second section of interview questions geared towards stage two, transition. Here participants were asked questions about how their time between high school and college was spent and if any preparation for college took place. The final section of interview questions measured incorporation. Questions were asked about student involvement within the university and the difference it made in their overall experiences.

Each participant was asked the same set of standard questions, but it was important to me that I capture the raw feelings of each participant. Sometimes respondent's answers to questions lead to a discussion about topics that were not included in the interview guide and I let these conversations flow thus being able to integrate multiple perspectives. According to Weiss (1994), "When wanting to describe an organization, development, or event that no single person could have observed in its totality, qualitative interviews are necessary. Standardized questions won't work because every respondent will have different observations to contribute" (p. 9). By allowing conversation to flow organically between interview questions I gave myself a better chance of collecting as much relevant and accurate data as possible.

I used a combination of convenience and snowball sampling to gather my sample. Convenience sampling gave me a jumpstart on contacting former WVU students because I know 
several. For the current WVU student interviews I used snowball sampling. The African American population at WVU is close-knit and I attempted to avoid my friend groups or associates when gathering my sample. The center for Black Culture and Research at WVU helped me to become aware of campus organizations and activities that are focused on African American students. I have attended several events implemented through the center including informational meetings about black student clubs and organizations. Gaining that familiarity benefited me by being more knowledgeable about possible topics and concepts that were mentioned by my participants. Attending these events also gave me an idea of how relevant these black student clubs and organizations are on campus.

\section{Results}

I broke down my interview into three sections. Each section measured a different stage of Tinto's Individual Departure theory. I evaluated and coded each section of the interview separately. This interview structure helped to find significance or lack thereof in each stage of the theory as it pertained to the experiences of African American students at the university. Upon the conclusion of my interviews, I concluded that although Tinto's theory Three Stages of Individual departure did indeed have an effect on the in the overall experience of African American students at WVU, some respondents reported experiences that challenged his framework as well.

Tinto identified stage one of individual departure as separation from membership in communities of the past such as high school, family and local areas of residence. He noted that a successful transition into college involved some form of rejection from past communities and some degree of transformation. For this portion of the interview I focused on themes of rejection of values and norms and levels of successful and unsuccessful transitions mentioned by the 
participants. What I found was that all participants reported having a strong bond with their family and a strong attachment to the values and beliefs that they instilled in them. According to Tinto, a successful transition involves some form of rejection from past values and beliefs and some degree of transformation. This did not seem to be the case for my participants. Students mentioned to me time and time again the most important value instilled in them was pride in their culture and where they come from. When asked if adhering to these values had been challenging during their time at WVU, the response was unanimous - no. Students say they never felt as though they had to be cautious of their blackness or felt the need to adapt to white ways of dress or acting. When asked if you had been able to oblige by personal values during your time at WVU one student reported,

"My sense of pride already prepared me for how to be black around white people, like I really don't care, it doesn't bother me. I grew up being proud of who I am and my surroundings at WVU didn't change that."

Although the rejection of personal values and beliefs from family was not something that was found in this particular group, what was found though was the rejection of values and beliefs instilled from past areas of local residence and the adaption of new ones. Majority of the participants of this study reported being from urban, predominately black neighborhoods. WVU though, is located in a rural predominately white town. When describing their hometown, participants mentioned the many precautions they would take on a daily basis to ensure their safety. For example, students would avoid certain parts of their neighborhoods, not leave their home after a particular time, not attend parties where there may not know all attendees etc. During their time at WVU though, they adapted higher levels of trust for their surrounding areas. Many described the rural WVU/Morgantown area to be much safer than their hometowns thus 
leading them to take more risk with their social behaviors. This included attending parties that were not hosted by close friends, being willing to stay out late at night, go places alone etc.

"The people here are so friendly. I could be walking down the street and some random person would just be like 'hi, how are you' I'm not use to that where I'm from. Where I'm from we all kind of stay to ourselves, but being here taught me to open up more and be more willing to try new things".

The feeling of being in a safer environment in comparison to home did not seem to have a major effect on student persistence. Students reported that this aspect did not play a role in their decision to remain or withdraw from the university. Instead, this aspect seemed to aid the social life of the student outside of the academia.

Stages two and three of Tinto's theory of Individual Departure held the most significance when attempting to uncover why students of color leave or choose to remain at WVU. Stage two, transition, is described as the time between high school and college. One aspect of a successful transition is dependent upon the degree to which students have begun the transition process prior to arriving on campus. This includes, but is not limited to, completing summer college courses, or participating in university programming offered by your institution. It was here that I found how important and impactful university programming was to incoming African American freshmen students attending PWIs.

During my interviews junior and senior participants constantly spoke about the impact programs such as STARS and HYPE Day (which no longer exists) had on them and their decision to remain at WVU. As mentioned before STARS serves as a summer bridge program to help prepare a select number of African American students academically and socially for their time at the university. Surprisingly, many older participants of this study (Junior's and Senior's) were STARS members and vividly described the impact the program had on them. 
"Through the STARS program I learned a lot of foundational history and how to identify as a black man at a PWI. I feel that is important for any black student going to college. The STARS program helped tremendously with that social transition I think many of us black students face coming to a PWI."

The other WVU program that had a large impact on African American students was HYPE Day (Helping You Pursue Excellence Day). HYPE Day was a student recruiting event geared towards all prospective African American students. The goal of HYPE Day was to help students of color find the resources on campus geared towards African Americans that otherwise may be challenging to find. HYPE Day served as a time to highlight the abundance of resources on campus for students of color. Guests were given the option of choosing from a variety of informational sessions, including a talk with residential educations and WVU housing, financial aid, the Center for Black Culture and Research and other various student and faculty panels.

HYPE day guests then ate lunch in a residence hall and were given a presentation from a WVU assistant professor for Educational Leadership Studies. This study's participants who attended HYPE day expressed how it "sealed the deal" for them and their decision to attend the university.

"During my campus visit I attend HYPE Day and the school hooked me up with another black current WVU student who was in my intended major and I basically shadowed her for a day. The fact that they did that for me, being a black student and all, I felt that WVU actually cared so I decided to come here."

As of fall 2012 HYPE Day had been discontinued and the only existing summer program geared towards African Americans is the STARS program. This proves to be problematic because the STARS program is invitation only and only accepts between 15-20 students each summer- a very small portion of the black community at WVU. This leaves the remaining black population with little to no options in terms of WVU programming that could help aid with a successful transition into the university. 
The younger participants of this study, freshmen and sophomores, did not participate in the STARS program nor were they given the opportunity to participate in HYPE day due to discontinuation. Not only did these students fail to participate in university summer programming, but there was also a lack of participation in summer programming to help prepare them for college outside of the university. When asked how this made the students feel they reported feeling as if they were just "thrown" into the university without any proper guidance. In fact, the lack of preparation seemed to be a major factor for students who had decided to withdraw from the university.

One participant who withdrew from WVU after the conclusion of her first semester of her sophomore year explained that she felt the university did not have much to offer for her or people who looked like her. When asked if she knew about several programs and organizations that existed on campus geared toward African American interest, she had no idea that they existed.

"My hometown is very diverse in culture, which is why when I came here and saw little cultural diversity, I was a bit surprised. As far as I am concerned there is only ONE club geared toward the African American community (African Student Association). I had no idea these other ones were here."

This lead to the final stage of Tinto's theory examined through interview questionsincorporation. Here as mentioned before is where students become integrated into the communities of their institution. This could be done by joining sports teams, student associations etc. Incorporation proved to be an important, if not the most important factor in student persistence at WVU.

Every participant of this study mentioned thoughts of transferring from WVU at some point in time. These thoughts came prior to their involvement on campus. When asked what 
made them change their mind and decide to stay, across the board it was credited to their involvement in campus organizations and clubs geared towards the African American community and beyond. Not only did involvement in these activities give these students a sense of belonging, it gave them a sense of importance as well. Students felt that their involvement in these activities gave them a voice at the university. One student who was involved in several programs at WVU had this to say regarding his involvement at the university:

"When I walk into SGA meetings, RA staff meetings, NAACP meetings etc, a lot of the time I am the only black man there. To me that's saying you are represented, but you are also the representative. So I make sure that my community is represented well-so that's what's keeping me here".

Participants who did not participate in any campus clubs or organizations still discussed thoughts of transferring from the university or have already done so. When asked why they chose not to participate in any activities, majority stated that they did not know these organizations existed or that they felt the organizations geared towards the black community were "weak". A student who withdrew from the university had this to say on the issue:

"I wish the non-Panhellenic fraternities and sororities were a lot more prominent here, but the way they advertise doesn't really get them noticed you know? They don't go looking. Everyone looks for them. While the other white frats actually go out and search for members. That's the only reason I wanted to go leave and go to an $H B C U$, just for that."

When asked what was meant by a weak organization I received identical answers from both organization members and non-organization members. Participants felt that student involvement within these orgs was low in numbers and the promotion of these clubs and orgs were slim to none. One participant when asked why she chose to involve herself in student organizations geared towards African Americans had this to say:

"The lack of unity foreal. The black community seemed to be so separated and I felt that part of the reason was because there really weren't any popping organizations that people would want to get into. So I'm trying to do things like bring back like the Black Student Union. Basically I want us to have programming that black students would actually want to come to". 
I was also able to speak with the president of one such club and asked him how he felt about the status of WVU black clubs and organizations. When I asked if he agreed that the orgs and clubs were weak he stated,

'Yes, and it's really sad. We have potential, but we can't- and I say we like every student organization, especially the black ones, can't function without student support. I don't know if we are doing something wrong or students are disengaged or they found other out groups of commonality, but no. The black orgs here are weak. We really need that support from students. We need to create a dialog where we can reach all of our students. We are very small in numbers and without student involvement I think that makes student leaders lose momentum and they stop caring. Once they stop caring that gives the students even more reason not to care."

Another participant, when asked why he did not join any black campus clubs or organizations on campus had this to say,

"Why would I? The people who run it don't seem like they even care for real and that makes me not want to join. Why waste my time with that? Like if you don't care why should I?"

Although previous research states that $62 \%$ of black students at PWI's felt campus orgs did not appeal to their interest this did not seem to be the case for WVU. The programming was there, but its execution is perceived as weak from both student leaders and potential student members, thus leading to a low number of student participation. The lack of student participation in these programs does not seem to fall on the backs of the university, but the student leaders. These leaders have not found the platform needed to be able to appeal to other African American students. There is a disconnect and lack of communication between student leaders and potential student members. The student leaders feel they do promote their activities and functions, but potential student members feel the promotion is weak and therefore they do not care to participate. This in turn may have an effect on the student leader's motivation to put forth $100 \%$ effort into their programming and its promotions which is why they may be perceived as weak by potential student members. 


\section{Discussion}

From the results of this study I concluded that Tinto's theory, Stages of Individual Departure as it pertains to persistence of African American students at WVU is relevant in two of its stages: transition and incorporation, but not stage one, separation, was not a significant factor in the participants decision to withdraw or remain at the university. In fact, the separation from past communities had an interesting effect. According to Tinto, a successful transition into college involves some form of rejection from past communities and some degree of transformation. For the participants of this study, rejection and transformation had a negative effect that led them to engage in more risk-taking behavior. Participants felt that WVU provided a safer environment than their hometowns which made them more comfortable engaging in activities that they would not do otherwise (partying with strangers, staying out late, going into foreign territory etc). Although these students felt "safe" engaging in these types of activities at WVU it doesn't take away that the students may be potentially putting themselves in harm's way.

Participants also reported that they did not feel the need to abandon previous cultural norms, another aspect of stage one which according to Tinto is a big challenge for college students. When asked about the relationships participants had with other students, they reported that the low African American population caused them to gravitate even more to the African American community thus creating predominately black friend groups. This may explain why these students did not feel the pressure to adapt to the existing white culture around them because their immediate circle mostly consisted of those who looked like them.

Stages two and three, transition and incorporation, held the most weight when it came to a student deciding to withdraw or remain at WVU. The success of these two stages seem to rely 
upon two different parties; a successful transition seems to lie on the backs of the university and successful incorporation seems to lie on the backs of the student body, but both rely on one another. A successful transition can be completed through summer programming provided by the university. In the past three years WVU summer bridging programming geared towards the African American community has decreased in numbers and the most prominent one is not accessible to all incoming students (STARS). This posits an issue for majority of the incoming African American freshmen who now are forced to find their own way and seek out people and activities geared towards their interest at a university where more than half of the student body does not look like them. It should be taken into consideration that majority of the African American students who attend WVU, and the ones who participated in this study report being from urban and less fortunate areas.

This is all the more reason as to why summer programming to prepare students for their experience at a PWI is important to have because it may not be available or deemed necessary from in their urban hometowns. Participants of this study who did not complete any summer programming related to WVU had little knowledge of black orgs that existed on campus. Without this programming many students enter the university lost and experience feelings of isolation. It is important to expose students to these types of activities during freshmen year because as Tinto mentioned, a student's first year experiences are detrimental to their overall student success and persistence. This programming also aids the incorporation stage by making students familiar with activities and orgs on campus that are available to them and are geared towards African American interest. This exposure could help increase student involvement upon arrival at WVU, thus leading to successful incorporation at the university. The increase in student involvement at the freshmen level could help change the belief that the black student 
orgs are "weak". This increase in student involvement could also help to change the attitudes of those student leaders. Student leaders could then put forth the effort into their particular club or organization and gain back the momentum that was loss due to lack of student involvement.

\section{Conclusion}

It is my hope that the results of this study could further improve the quality and shape the policies WVU has in place for achieving diversity thus creating higher retention rates for students of color. Stage two of Tinto's model, transition was reported to be the most important to participants. For this reason WVU should consider reinstating more summer programming aimed at prospective African American students or consider bringing events such as HYPE Day back into notion. This study proved that such programming had a positive effect on a student's decision to enroll at the university and paved the way for them to make connections and create relationships that contributed to their decision to stay. Younger students who participated in in this study, (freshmen and sophomores) who did not receive these opportunities to participate in summer programming have either transferred from the institution or still have thoughts of doing so. These findings may help the WVU 2020 plan obtain goal number three: ensuring the success of minority students mentally, socially and academically. 


\section{Appendix A}

\section{Interview Guide}

These interview questions aim to touch on all three phases of Tinto's theory of Individual Departure (excluding the first question).

All respondents will remain anonymous

- Why did you choose to attend WVU?

First section measures level of separation

- Could you describe your hometown?

- How would you describe the difference between WVU and your hometown?

- Would you consider where you live to be rural, urban or suburban?

- Was your hometown diverse in culture?

- $\quad$ How would you describe the diversity within your high school?

- $\quad$ Do you the learning styles differ from your high school and WVU?

- What were some activities you were involved in back home?

Are you participating in similar activities here?

- Why or why not?

- $\quad$ Could you describe for me the kind of relationship you have with your immediate family?

- What were some values instilled in you that you believe to be a product of your community back home?

- $\quad$ Have you been able to oblige by those values during your time at WVU?

Why or why not?

- $\quad$ Have you adapted to any new values or norms during your time at WVU?

- If so, do these values or norms conflict with your existing values?

\section{This section measures level of transition}

- Think back to your summer before arriving at WVU. What did you do?

- Do you think these activities prepared you for college?

Why or why not?

- $\quad$ Do you think the effort was made by the institution to prepare you for the WVU experience prior to arriving on campus?

- If not, what are some things you wish would have been done? 


\section{This measures levels of Incorporation}

- $\quad$ How would you describe the diversity at WVU?

- $\quad$ Do you think WVU does a good job of promoting diversity?

Why or why not?

- $\quad$ Are you involved in any campus clubs or organizations?

If so, which ones?

If not, why not?

- Are you involved in any clubs or organizations around the area that are not affiliated with WVU?

- Did your involvement in these orgs. Contribute to your decision to remain at WVU?

- $\quad$ Do you think there are clubs and organizations on campus that gear towards African American interests?

If so, which ones?

- How would you describe your relationship with other black students?

- How would you describe your relationship with white students?

- How would you describe your relationship with faculty and staff?

- $\quad$ Have you ever been made uncomfortable by a peer because of your race?

Explain in detail

- Have you ever felt as if you were singled out by a professor because of your race?

Explain in detail 


\section{Demographics}

- $\quad$ Sex: M or F

- Age:

- $\quad$ Undergraduate level (Freshman, Sophomore, Junior, Senior)

- Major:

- Hometown: 


\section{Appendix B}

\section{W. West VirginiaUniversity. \\ Office of Research Integrity and Compliance \\ 886 CHESNUT RIDGE ROAD MORGANTOWN, WV 25606}

\section{Acknowledgement Letter Exempt Initial Protocol Review}

\section{Action Date}

To

From

Approval Date

Expiration Date

Subject

Protocol Number

Title
02/01/2016

Jesse Wozniak

WVU Office of Research Integrity and Compliance

$02 / 01 / 2016$

$01 / 31 / 2019$

\section{Acknowledgement Letter Exempt Initial Protocol Review}

1601983423

Withdrawn: Why Students of Color Leave WVU

The above-referenced study was reviewed by the West Virginia University Institutional Review Board IRB and was granted exemption in accordance with 45 CFR 46.101.

- This research study was granted an exemption because the Research involves educational tests, survey procedures, interview procedures or observation of public behavior and (i) information obtained is recorded in such a manner that human subjects cannot be identified, directly or through identifiers linked to the subjects; and (ii) any disclosure of the human subjects responses outside the research could not reasonably place the subjects at risk of criminal or civil liability or be damaging to the subjects financial standing, employability, or reputation [45 CFR 46.101(2)]. All exemptions are only good for three years. If this research extends more than three years beyond the approved date, then the researcher will have to request another exemption. The following documents have been acknowledged for use in this study and are available in the WVU+kc system:

Documents reviewed and/or approved as part of this submission:

Cover Letter Interview.docx: 2016-01-26-05:00

Appendix IRB.docx: 2016-01-26-05:00 
Documents for use in this study have been acknowledged and are available in the WVUkc system in the Notes and Attachments section of your protocol.

The Office of Research Integrity and Compliance is here to provide assistance to you from the initial submission of an IRB protocol and all subsequent activity. Please feel free to contact us by phone at 304.293.7073 with any question you may have. Thank you.

WVU Office of Research Integrity and Compliance

Date:02/01/2016

Signed:

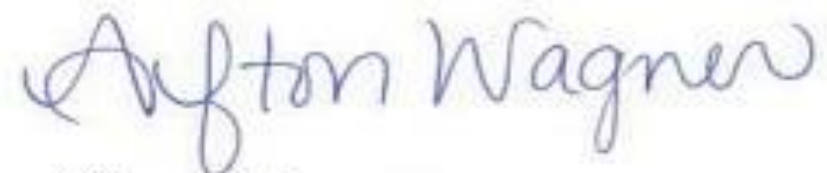

Afton Wagner IRB Administrator 


\section{References}

Davis, D. W. (1997). The direction of race of interviewer effects among african-americans: Donning the black mask. American Journal of Political Science, 41(1), 309-322.

Davis, M., Dias-Bowie, Y., Greenberg, K., Klukken, G., Pollio, H. R., Thomas, S. P., \& Thompson, C. L. (2004). "A fly in the buttermilk": Descriptions of university life by successful black undergraduate students at a predominately white southeastern university. The Journal of Higher Education, 75(4), 420-445. doi:10.1353/jhe.2004.0018

Feagin, J. R., \& Sikes, M. P. (1995). How black students cope with racism on white campuses. The Journal of Blacks in Higher Education, (8), 91-97. v

Gennep, Van. (1960). The Rites of Passage Chicago: University of Chicago Press

Love, D. (2008). revitalizing retention efforts for african-american college students at predominately white institutions. Allied Academies International Conference. Academy of Educational Leadership. Proceedings, 13(2), 41.

Mow, S. L., \& Nettles, M. T. (1990). Minority access to and persistence and performance in college: A review of trends in the literature. In J. Smith (Ed.), Higher education: Handbook of theory and research.

Rhodes, P. J. (1994). race-of-interviewer effects: A brief comment. Sociology, 28(2), 547-558. doi:10.1177/0038038594028002011

Sedlacek, E. William. (1970). Black Students on White Campuses: Twenty Years of Research. Journal of college student development

Tinto, V. (1993). Leaving college: Rethinking the causes and cures of student attrition (2nd ed.). Chicago: University of Chicago Press.

Weiss, R. S. (1994). Learning from strangers: The art and method of qualitative interview studies. New York: Free Press. 